\title{
DEATHS FROM DOMESTIC FALLS AND FRACTURES
}

\author{
T. P. EDDY
}

Department of Human Nutrition, London School of Hygiene and Tropical Medicine, London W.C.1

Over the past 10 years fractures in the elderly and their relationship to osteoporosis and other causes of bone fragility have been the subject of increasing interest. The investigation of current incidence of morbidity by the Medical Research Council's Working Party on Fractures in the Elderly resulted in a report on the incidence of fractures in persons over 35 years of age by Knowelden, Buhr, and Dunbar (1964). Other important related studies have been by Buhr and Cooke (1959), Nordin, MacGregor, and Smith (1966), and Bollet (1968). All these studies show a similar sex and age incidence for certain types of fracture, particularly fractures of the femoral neck, of the upper part of the humerus, and of Pott's and Colles' types of fracture. The incidence of these fractures increases sharply over 55 years of age and the incidence in elderly women is two or three times that in men.

Nordin et al. (1966) have described the same age and sex incidence for osteoporosis, and have related the development of osteoporosis with age to the occurrence of fractures, particularly lower forearm fractures in women and fracture of the proximal femur. Recently, Nordin (1971) has suggested that the progression of osteoporosis with age may be attributable partly to vitamin D deficiency. A leading article (British Medical Journal, 1971) refers to hormonal, nutritional, physical, and circulatory causes of osteoporosis and to a significant incidence of vitamin $\mathrm{D}$ deficiency in the elderly, noting that, because the health and nutrition of children is now better than it used to be, the present generation may suffer less osteoporosis when they become old. Clearly there are factors additional to strictly defined osteoporosis, leading to increased bone fragility and liability to fracture in old age. Buhr and Cooke (1959) have called the typical age-sex incidence of fractures of this kind the post wage-earning fracture pattern. The fractures concerned occur predominantly in cancellous areas, usually at the end of long bones; characteristically they result from minor trauma which would have had no serious results earlier in life.
Some fractures in the elderly result from internal causes. The most common external cause is a fall inflicting minimal violence to a fragile bone. Knowelden et al. (1964) found that femoral fractures were largely the result of falls at home. Falls, particularly falls at home (which in themselves may be trivial, mere slips to the floor), are the most common accidents of the elderly with the highest rate of accidental deaths. Their aetiology and importance or, as he called it, 'the natural history of falls in old age', have been described by Sheldon (1960). Fractures, particularly of the femur, are the most common injuries causing death in the elderly. Domestic falls have the same pattern of incidence as the post wage-earning fracture pattern, with a high incidence in elderly women.

Though the current morbidity from these causes has been studied, secular trends of mortality over longer periods of time appear to have received less attention, though they present features which are of considerable interest and may be informative.

\section{Comparative Mortality of Falls and FRACTURES}

Since 1950 the Registrar General's annual Statistical Review of England and Wales, using the International Classification, has tabulated deaths caused by accident and injury according to the nature of injury (' $N$ ' classification) as well as by external cause (' $E$ ' classification). Deaths attributed to fractures of the neck of the femur (N820) occurring in different age-groups follow the same general post wage-earning fracture pattern of incidence described above. There are negligible numbers of deaths from fractures of the femoral neck below 55 years of age, but over 55 age-specific rates for women are $50 \%$ to $80 \%$ above those for men. Mortality from fractures of other parts of the femur (N821), of the tibia and fibula (N823), and of the humerus, radius, and ulna (N810-19) shows the same pattern. Mortality rates for some of these fractures are shown in Figure 1 a-c. 

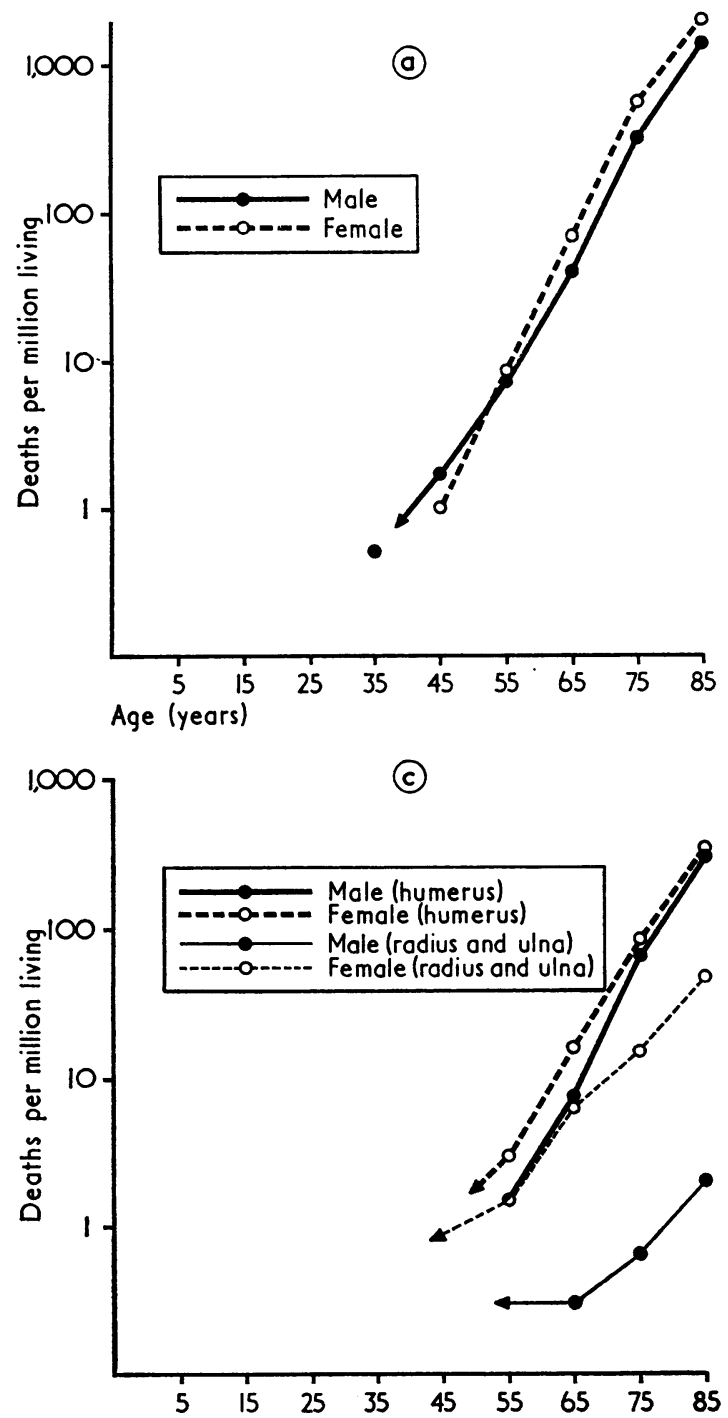

Age (years)

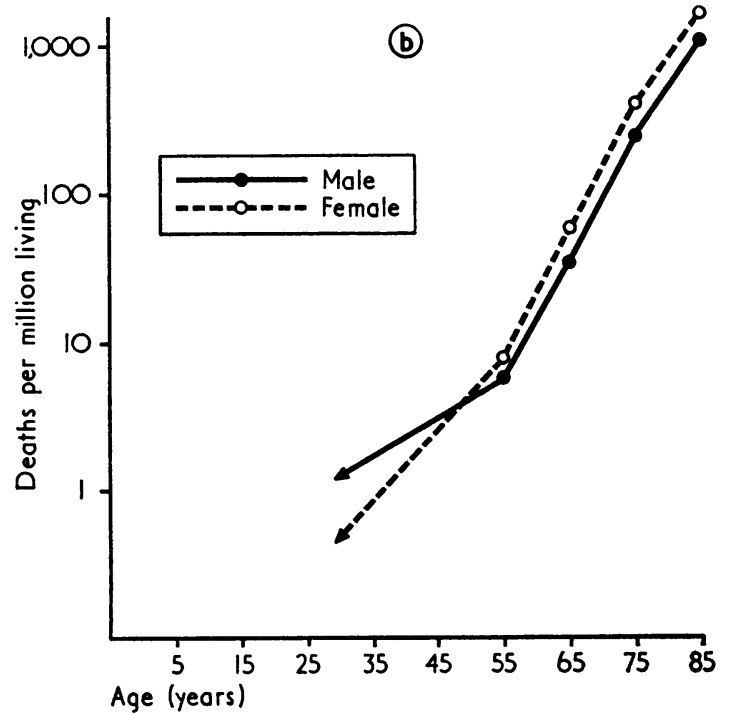

(a)

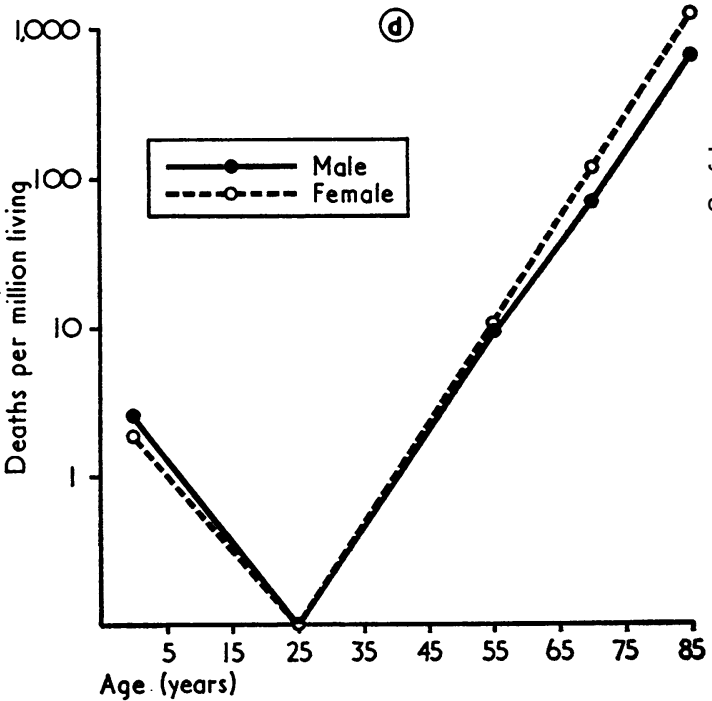

Fo. 1-Mean annual death rates of men and women per million living at age, 1965-68: (a) fractured neck of femur (N820), (b) other fractures of femur (N821), (c) fractures of humerus, radius and ulna (N810-19), (d) domestic and residential falls "on the same level" (B903) and "unspecified" (E904) in Table 18e for 1965-7 and (E885-7, 8th revision) in Table 18e for 1968 of the Registrar General's Statistical Reviews.

Before 1950, the ' $N$ ' classification for accidental deaths was not used, but in the classification of violent deaths reported by coroners, accidental deaths due to falls in a house, room, etc., and falls out of bed have the same post wage-earning pattern. These deaths are recorded under the old International List No. 186 in Table 25 of the Registrar General's Statistical Review for 1949 and in corresponding tables in preceding reviews. A similar category of accidental deaths since 1950 is included in falls at home 'from one level to another', 'on the same level', and 'unspecified' (E902-4, 7th revision; E884-7, 8th revision; Table 18 of Statistical Reviews)*. They exclude such gross forms of accidental violence as falls downstairs or falls out of windows, which are separately classified, and death probably resulted from minimal violence leading in most cases

\footnotetext{
- All but the final statistics for 1968 are designated as E902-4 in the Registrar General's tables. With the 8 th revision of the International Classification of Diseases, the code numbers for these accidents were changed to E884-7.
} 
to fracture. Mortality rates for E903-4 in Figure 1d show the same pattern in relation to age and sex, and the same slope, as deaths from fractures of the femur. As the statistics were returned by coroners as accidental deaths or with open verdicts, they presumably excluded falls caused by cerebral and cardiovascular disasters, which would have been attributed to natural causes. It is therefore a reasonable assumption that deaths from falls of the elderly before 1950 would show the same trends as deaths from fractured neck of femur and other fractures with the post wage-earning pattern.

To test this hypothesis, annual comparative mortality ratios (CMR) of all deaths between 1950 and 1968 over the age of 65 years attributed to fracture of the neck of the femur (N820), other parts of the femur (N821), tibia and fibula (N823), and the upper limb, which were mostly of the humerus, and Colles' fractures (N810-19), were compared with the CMRs of falls at home on the same level (E903) and unspecified (E904). These categories of falls registered after 1950 in Table 18a of the Registrar General's Statistical Reviews are similar to the categories of falls in house, room, etc., and falls out of bed, given in Table 25 by the Registrar General for 1949.

The results are shown in Figure 2. Although the annual mortality of women over 65 years of age

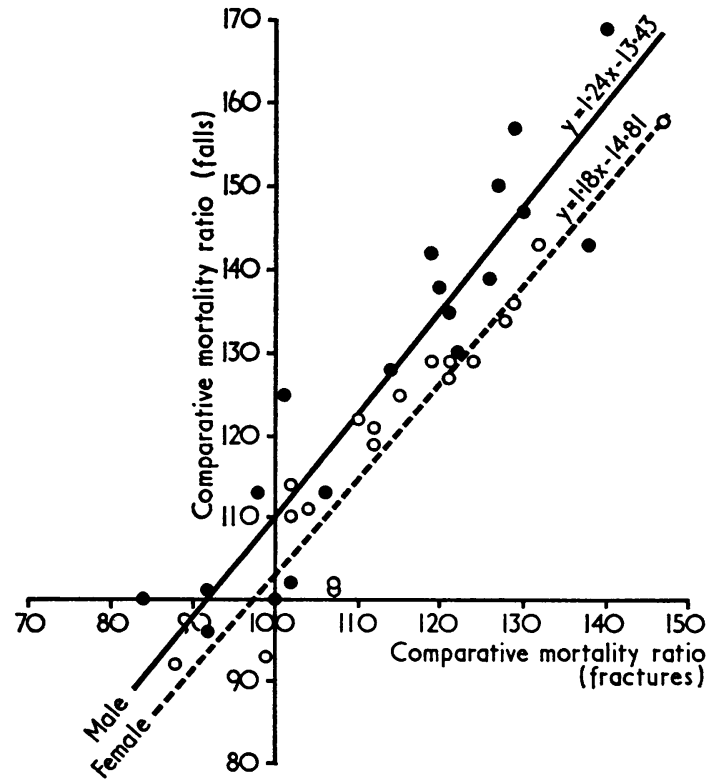

FIG. 2-Correlation between 19 annual comparative mortality ratios (CMR) for domestic falls (E903 and 904) and CMR for fractures of limbs $(N 810-21,823)$ for men and women 65 years of age and over. The ratios are calculated separately for men and women from values of 100 for 1951 . For men, $r=0.94$; for women, $r=0.93$.

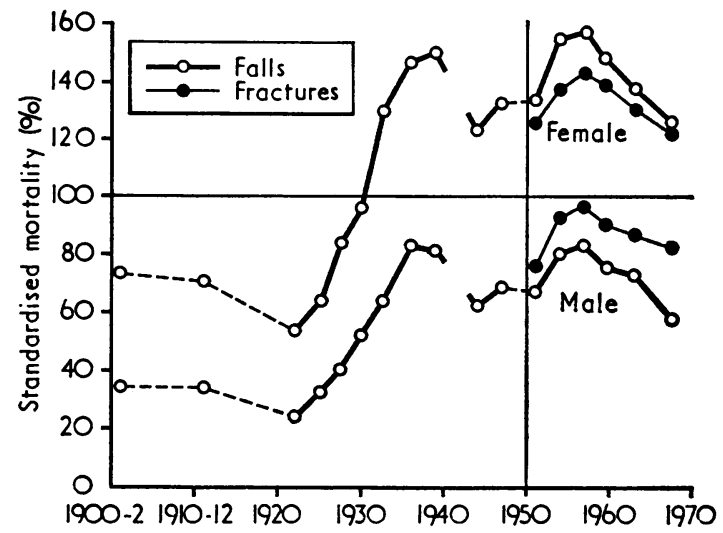

FIG. 3-Comparison of mortality of men and women aged 55 years and over from domestic falls and fractures of limbs. Standardized mortalities per cent after 1949 are the expected deaths expressed as twice the percentage of total male and female deaths occurring in the twice the percentage of total male and female deaths occurring in the standard population in 1950-52. The graph therefore shows a total of
200 expected deaths in 1950-52. Before 1950 they are related to 200 200 expected deaths in $1950-5$.
expected deaths in $1949-50$.

was three to four times that of men, there is a close relationship between mortality from limb fractures and mortality from domestic falls in both men $(r=0.94 ; P<0.001)$ and women $(r=0.93$; $\mathbf{P}<0.001)$ and the relationships for both sexes are similar.

\section{Secular Trends in Mortality}

The standardized mortalities shown in Figure 3 give a record for falls in rooms and out of bed over triennial periods between 1900 and 1949 . The record is continuous from 1920 except for two breaks of two years in 1942-43 and 1946-47. From 1950 to 1968, Figure 3 shows standardized mortalities for domestic falls (E902-4, Table 18a, Statistical Reviews 1950-67; E884-7. Review for 1968) together with those for fractured limbs (N810-21, 823, Table 17 of Statistical Reviews). The standardized mortalities for fractures from 1950 to 1968 were obtained by applying age-specific mortality rates of each sex for age-groups 55-, 65-, 75-, and 85+ years to the standard combined male and female population at age in 1951. Those for domestic falls after 1950 were calculated from mortality over the age of 65 , as statistics for smaller agegroups are not published. The expected deaths so calculated have been expressed as twice the percentage of total male and female deaths from fractures and falls occurring in 1950-52 (i.e., they are based on a standard of 200 combined male and female deaths in the standard period). Deaths from falls before 1950 are similarly based on 200 deaths from falls in 1949-50. This use of the older method of applying successive mortality rates to a standard population, expressed as percentages of a standard 
mortality, facilitates comparison of trends before and after the changes in classification and registration in 1950 and allows a direct comparison between mortalities of men and women uninfluenced by the different age-structures of male and female populations.

At the changeover from one classification to another in 1949-50, the numbers of deaths at age 65 and over from domestic falls, shown in Figure 3, were: for 1949, 385 men and 1,257 women; for 1950, 400 men and 1,347 women. The numbers of deaths in these two classifications at the relevant time approximated closely.

\section{Correlation between SeX Incidences of MORTALITY}

Although the mortality of women from these causes is shown in Figure 3 to be about double that of men, the mortality of men showed a high correlation with that of women. For the 19 years 1950-68, the coefficient of linear correlation between annual CMRs of men and women over 65 years of age was $r=0.88$ for fractures $(\mathrm{N} 810-21,823)$ and $r=0.90(P<0.001)$ for domestic falls (E902-3). Over the whole range of falls from 1920 to 1968 , shown in Figure 3, the coefficient of correlation between triennial mortality of men and women was $r=0.98(P<0.001)$.

\section{Correlation between Mortalities at Different Ages}

Figure 4 shows the relationship within each sex between the annual fracture mortalities of two different age-groups since 1950. If the whole range of triennial mortalities for falls shown in Figure 3 is considered, there are similarly high correlations between these age-groups for each sex $(r=0.88$

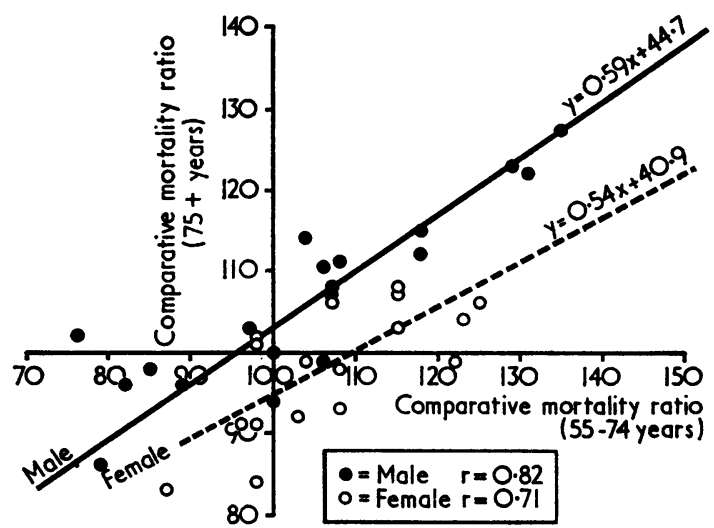

FIG. 4-Correlation between 19 annual CMRs of fractured limbs (N810-21, 823) at age 55-74 years and at age 75 years and over in men and women. For men, $r=0.82$; for women, $r=0.71$. and $0 \cdot 89$ ). If comparisons are made between agegroups from opposite sexes over the whole triennial range from 1920 to 1968 , there are also highly? significant correlations: $r=0 \cdot 80-0 \cdot 89$. These high $\vec{F}$ correlations suggest that some common factors affected mortality in each sex and age-group, even $\frac{C}{0}$ though their total experiences of mortality were $\bar{c}$ substantially different.

\section{Discussion}

Throughout life the skeleton is modelled by a $\vec{\theta}$ continuous process of bone formation and resorption. Vaughan (1970), describing mineral and $\vec{\omega}$ skeletal homeostasis, points to the obvious remodelling during the growth of the skeleton in the first 20 years of life, but thereafter it is estimated that $3-5 \%$ of the adult skeleton is being actively $\%$ remodelled at any given time.

Garn (1970) has described the growth and $\vec{\omega}$ moulding of tubular bones resulting from gains and $ᄋ$ losses of cortical bone. Subperiosteal apposition takes place at different rates during growth and continues throughout life. At the endosteal surface $\stackrel{0}{0}$ there are alternating phases of resorption and $\stackrel{5}{+}$ apposition, followed by an adult phase of resorption $\overrightarrow{0}$ continuing throughout life. The patterns of res sorption and apposition in the two sexes are different The early increments and later losses of skeletal weight which result from the varying balance between apposition and resorption are illustrated in Figure 5. Garn has also shown that larger body size and greater height are associated with less bone loss, and that the early accumulation of bone is the best defence against later bone loss. In this he agrees with Fourman and Royer (1968), who consider that the amount of calcium stored by the age of 20 is more important than day-to-day turnover at the age of 60 . Recently, Stewart, Sheppard, Preece, and Exton-Smith (1972) studied the histology and ash-content of post-mortem

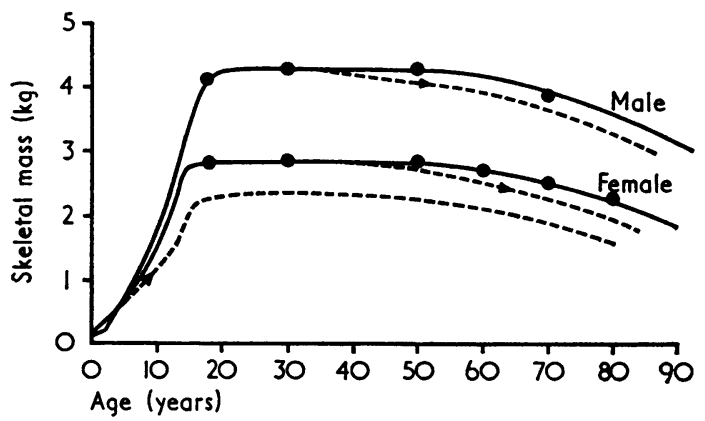

FIo. 5-Changes in skeletal mass with age, adapted from Garn's (1970) tables. The dotted lines sugzest deviations from normal due to adverse factors which may occur early or late in life and are adapted from Bollet (1968). 
specimens of bone from 76 elderly hospital patients. Although four had osteomalacia due to vitamin D deficiency, they concluded that bones densely calcified in early life will be less liable to develop pathological osteoporosis when mineral is lost in later life.

Exton-Smith, Millard, Payne, and Wheeler (1969) have constructed a model showing the pattern of bone development and loss with age, which closely resembles the curve for adult ages shown in Figure 5. Their percentile curves of development reach a maximum cortical area at the age of 30-40 years with a subsequent decline. Only a longitudinal study, in their opinion, will show whether changes from one percentile rank to another could occur as the result of disease, physical activity, therapeutic agents, or nutrition. In Figure 5 it is suggested that such changes may occur, leading either to failure in the full attainment of skeletal mass in early adult life or to accelerated loss thereafter.

\section{Historic Causes of Mortality Differences}

Changes of this kind affecting the size of attained skeletal mass or the rate of loss with age could account for the secular changes in mortality, if the mortalities shown in Figure 3 are indeed related to bone fragility. If the wartime recession in mortality is disregarded, the continual increase in mortality from the beginning of the century until 1960 corresponds to observed differences in stature of British adults. Boyne and Leitch (1954), in a review of available data of secular change in height, noted that the studies by Cathcart, Hughes, and Chalmers (1935), Clements and Pickett (1952), and Kemsley (1950), which were made independently at three different dates, show a decline in stature following the age of 25 years, and all show a sudden rise in mean height of age-groups born in the first 10 years of this century. The rise in mean stature was over $1 \mathrm{~cm}$ in women and over $1.5 \mathrm{~cm}$ in men. The decline in height with age in these surveys contrasts with observations made in the nineteenth century by Quetelet, Beddoe, Roberts, and others, who found no decline in height before the age of 50. Boyne and Leitch (1954) suggested that the changes which started at the beginning of this century, subsequent to the report of the Inter-departmental Committee on Physical Deterioration (1904), with an increasing provision of such welfare services as school meals, school health services, National Health Insurance, unemployment benefits, and old age pensions, through their effect on selective mortality, increased the proportion of the poorer social classes present in the older age-groups and so reduced the mean heights of those age-groups. They considered that it was possible that the height of young adult groups was reduced in the same way. In other words, there has been a greater survival of skeletal weaklings of small stature who had suffered from nutritional deficiencies, which included childhood rickets, and whose growth was retarded. The generation of elderly people coming into these mortality statistics since 1960 is that which showed the sudden increase in height to which Boyne and Leitch refer, and this may be one factor in the reduction of mortality.

Some support for a relationship betwen mean stature of the population and fracture mortality is shown in Table I. Mortality from fractures of the femur is higher in the north of England than in the south in both sexes. Wales and the Midlands are intermediate in both mortality and position. The data of Martin (1949) refer only to adult men, but Greenwood (1913) and Tuxford and Glegg (1911) give regional data for children with differences of $3-4 \mathrm{~cm}$ in height at age 14 years between north and south. The difference was probably exaggerated through bias caused by a greater proportion of rural areas sampled in the south, and differences in the age-incidence of the prepubertal growth spurt would affect height measurements around the age of 14.

The height statistics of Greenwood (1913) shown in Table I were obtained from 133 records of mean heights of school children in 1908-11 from education authorities in counties and boroughs which were classified by Greenwood as reliable. The children were drawn from the same generation whose mortality statistics 60 years later are given in the table, and Greenwood's data have been regrouped into the regions shown in the table. The National Service recruits of Martin (1949) are from a younger generation.

Possible Contemporary Social and EnVironmental Causes of Mortality Differences

Skeletal differences, attributable to historic differences in nutrition during the period of growth, cannot explain the high correlation between mortalities of different sexes and age-groups from year to year. These changes, impartially affecting groups with substantially different mortality and morbidity, appear to be associated with contemporary rather than with historic factors, particularly so with regard to the recession of mortality in the 1940s.

Vaughan (1970) distinguishes two functional factors in the maintenance of bone: skeletal homeostasis, the mechanical maintenance of a scaffold for other tissues, and mineral homeostasis, in which the bony skeleton resembles a bank, holding both deposit and current accounts with a currency of 
TABLE I

MEAN ANNUAL STANDARDIZED DEATH RATES 1966-69 PER MILLION POPULATION AT AGE 55 YEARS AND OVER FOR FRACTURES OF FEMUR (N220, 221) AND STATURES OF YOUNG ADULT MALES AND SCHOOL CHILDREN IN 3 URBAN/ RURAL AGGREGATES OF ENGLAND AND WALES

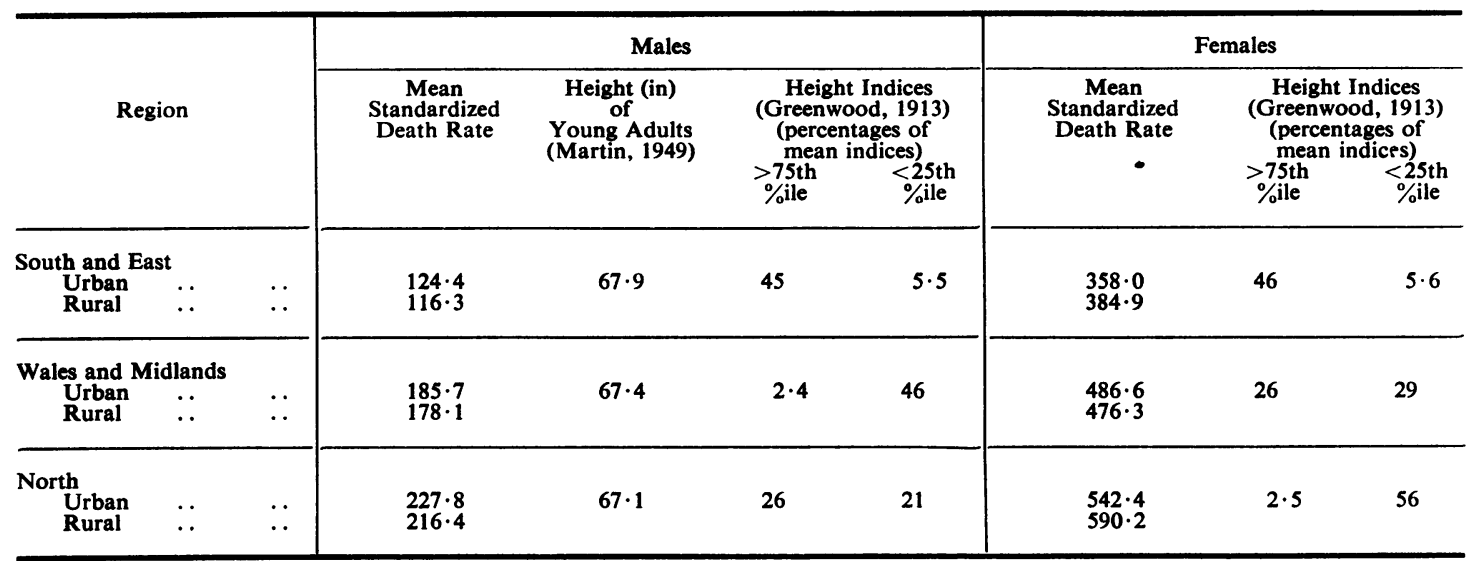

Mean death rates were calculated from annual death rates $1966-69$ per million living in age-groups $55-, 65-, 75+$ applied to estimated population at age 1967-68. Data supplied by General Register Office.

Greenwood's index for school children aged 5-15 was the percentage of the average height at age for the whole country 1908-11. He calculated a mean index for the schools of each education authority. The table shows the proportions of indices falling above and below the 75th and 25 th percentiles calculated from the variance of his indices. The differences in distributions between regions are highly significant $(P<0 \cdot 0005)$.

calcium, magnesium, and phosphate ions. The control and management of the bank is in charge of various hormones, together with vitamins $\mathbf{A}, \mathbf{C}$, and D. External factors acting upon the mineral homeostasis of a population would appear to be mainly nutritional, the adequate supply of minerals and vitamins and of energy for the system to work. An important external factor acting upon skeletal homeostasis is mechanical stress and pressure. This is shown dramatically in the osteoporosis and mineral loss occurring with confinement to bed, paralysis, and the recumbency and weightlessness of astronauts.

Fortification of flour and margarine with calcium and vitamin $\mathbf{D}$, with a corresponding increased intake of these nutrients during the war, might seem to be obvious nutritional improvements affecting bone in the 1940s, but they are improvements which were primarily directed to the prevention of rickets in the young. As these fortifications have continued ever since, the resumed trend of increase in mortality after the war remains unexplained.

The same objections apply to the attribution of lower mortality to improvements in treatment. The great advances in surgical treatment of fractures started in the 1930s, and those of anaesthetics in the 1940s. The ultimate effects of these improvements should have persisted and increased with the start of the National Health Service, but over the first 10 years of the N.H.S. there was an increasing mortality.
One contemporary factor which may have been associated with the fall in mortality, which coincides with the period of rationing and 'austerity', may be the increased activity of elderly people during the war years. From 1920 to 1940 was a period of increasing unemployment; 1940 to 1950 was a period of full employment when many people worked beyond the age of retirement. Elderly women did housework normally done by younger housewives who were employed on work of national importance, fuel was rationed, and public transport was much reduced. In these circumstances the general level of physical activity was unusually high. Following 1950 there has been a general increase in the use of power in industry, domestic work, and transport, probably leading to an increasingly sedentary life for the elderly.

Further evidence of the effects of contemporary social, and perhaps nutritional, factors in adult life is shown in Table II. Hospital discharge and death

TABLE II

MEAN ANNUAL HOSPITAL DISCHARGE RATES PER N 10,000 POPULATION FOR FRACTURES OF FEMORAL O NECK (N820); MARRIED AND UNMARRIED MEN AND WOMEN, 1965-67

\begin{tabular}{c|cc|cc}
\hline \multirow{2}{*}{$\begin{array}{c}\text { Age } \\
\text { (yr) }\end{array}$} & \multicolumn{2}{|c|}{ Men } & \multicolumn{2}{c}{ Women } \\
\cline { 2 - 3 } & Married & Unmarried & Married & Unmarried \\
\cline { 2 - 5 } 45 & $1 \cdot 6$ & $4 \cdot 1$ & $3 \cdot 1$ & $5 \cdot 1$ \\
65 & 9.3 & $25 \cdot 7$ & $30 \cdot 1$ & $42 \cdot 5$ \\
\hline
\end{tabular}

Data from Report on Hospital Inpatient Enquiry (Ministry of Health and General Register Office, 1967). 
rates of unmarried men treated for fractured neck of the femur are two and a half times those of married men and approach those of married women. The difference between married and unmarried women is not so great. Though total morbidity from all causes, as measured by hospital discharge rates, is generally higher in the unmarried, this particular difference is exceptionally high.

A historical review of mortality of this kind can be only speculative and suggestive in its discussion of the causes of secular changes. Many other factors-environmental, social, and nutritionalmay have had more or less importance in influencing trends in mortality than those mentioned in this paper. But one thing is clear; it does not seem likely that these consistent trends in mortality, affecting men and women of different ages with different mortality rates alike, can properly be attributed to the chances of violence, or that they are truly accidental deaths in the home. It is much more likely that these deaths are the results of some metabolic failure which has followed a definite pattern related to the social and nutritional experience during life.

\section{SUMmary}

Mortality of elderly men and women from fractures of the long bones is closely related to mortality attributed to falls in the home. The fatalities are two to three times more common in women than in men and increase with age, so resembling the general pattern of morbidity in limb fractures and osteoporosis.

From 1920 to 1940 there was a steady increase in mortality attributed to domestic falls. Mortality declined from 1940 to 1950 during the period of war and post-war 'austerity', and rose again to a peak in 1960 when it started to decline.

Though the mortality of elderly men was much lower than that of women, it was highly correlated with female mortality.

The secular changes in mortality may be related to secular changes in skeletal mass and stature originating in childhood in the nineteenth and early twentieth centuries. There also appear to be contemporary factors affecting the mortality of both sexes from time to time, one of which may be muscular activity and associated stress of the skeleton in the elderly.

\section{REFERENCES}

Bollet, A. J. (1968). Osteoporosis, or the osteoporosities? Amer. J. med. Sci., 256, 271.

BoYNe, A. W., and LeITCH, I. (1954). Secular change in height of British adults. Nutr. Abstr. Rev., 24, 255.
British Medical Journal (1971). Leading article: Osteoporosis. 1, 566.

BuHr, A. J., and CoOKe, A. M. (1959). Fracture patterns. Lancet. 1, 531.

Cathcart, E. P., Hughes, D. E. R., and Chalmers, J. G. (1935). The Physique of Man in Industry. Rep. Industr. Hlth Res. Bd. (Lond.), No. 71.

Clements, E. M. B., and Pickett, K. G. (1952). Stature of Scotsmen aged 18 to 40 years in 1941. Brit. J. soc. Med., 6, 245.

Exton-Smith, A. N., Millard, P. H., Payne, P. R., and Wheeler, E. F. (1969). Pattern of development and loss of bone with age. Lancet, 2, 1154.

Fourman, P., and RoYer, P. (1968). Calcium Metabolism and the Bone, 2nd ed., p. 255. Blackwell Scientific Publications, Oxford.

GARN, S. M. (1970). The Earlier Gain and the Later Loss of Cortical Bone, in Nutritional Perspective. Thomas, Springfield, Illinois.

General Register Office (annually). The Registrar General's Statistical Review of England and Wales for the year. H.M.S.O., London.

Greenwood, A. (1913). The Health and Physique of School Children. Published for Ratan Tata Foundation (London School of Economics) by P. S. King, London.

Inter-Departmental Committee on Physical DeterIORATION (1904). Report Vols. 1-3, Cd. 2175, 2210, 2186. H.M.S.O., London.

Kemsley, W. F. F. (1950). Weight and height of a population in 1943. Ann. Eugen. (Lond), 15, 161.

Knowelden, J., Buhr, A. J., and Dunbar, O. (1964). Incidence of fractures in persons over 35 years of age. A report to the Medical Research Council working party on fractures in the elderly. Brit. J. prev. soc. Med., 18, 130.

Martin, W. J. (1949). The Physique of Young Adult Males. Memor. med. Res. Coun. (Lond.), No. 20. H.M.S.O., London.

Ministry of Health and General Register Office (1967). Report on Hospital In-Patient Enquiry, Part I: Tables 1965-67. H.M.S.O., London.

NoRdin, B. E. C. (1971). Clinical significance and pathogenesis of osteoporosis. Brit. med. J., 1, 571.

-, MacGregor, J., and Smith, D. A. (1966). The incidence of osteoporosis in normal women: its relation to age and the menopause. Quart. J. Med., $35,25$.

SHeldon, J. H. (1960). On the natural history of falls in old age. Brit. med. J., 2, 1685.

Stewart, R. J. C., Sheppard, H. G., Preece, R. F., and Exton-SMith, A. N. (1972). Bone resorption in the elderly. Age and Ageing, 1, 1.

TuXFord, A. W., and GleGG, R. A. (1911). The average height and weight of English school children. Brit. med. J., 1, 1423.

Vaughan, Janet M. (1970). The Physiology of Bone, p. 19. Clarendon Press, Oxford. 